\title{
Use of seismic insulation for seismic protection of railway bridges
}

\author{
Ulugbek Shermuxamedov ${ }^{1}$, Said Shaumarov ${ }^{1 *}$, and Aleksandr Uzdin $^{2}$ \\ ${ }^{1}$ Tashkent State Transport University, 100067, Tashkent, Uzbekistan \\ ${ }^{2}$ Emperor Alexander I St. Petersburg state transport university, 190031, Saint Petersburg, Russia
}

\begin{abstract}
The problem of seismic protection of the bridge for the conditions of Uzbekistan is considered. The bridge is located in an area with estimated seismicity of 9 points. It has massive high supports on a natural foundation and relatively small and light spans. When selecting seismic isolation, this made it possible to use the span structures as a dynamic damper for the support vibrations in the direction along the bridge. Due to the damping effect, it was possible to achieve that the seismic forces in the support in the presence of the superstructure were less than in the free support without the superstructure. At the same time, the rigidity of fastening the superstructure to the support increased in comparison with the rigidity of classical seismic isolation, which facilitated the design of the supporting elements.
\end{abstract}

\section{Introduction}

In Uzbekistan, intensive transport construction is underway in seismically hazardous areas. At the same time, the supports of railway bridges turn out to be quite powerful and heavy. To perceive the seismic load, it is necessary to develop the support body, leading to an increase in the load [10-20]. This situation leads to the advisability of using special seismic protection methods, particularly seismic isolation of supports due to the use of movable supporting parts providing seismic isolation. Such a solution to a specific bridge is discussed below.

\subsection{The use of seismic isolation for seismic protection of railway bridges}

The area of application of seismic isolation for railway bridges is very limited. This is due to concerns due to the breakdown of the superstructure of the track on the bridge due to the high compliance of the supporting parts and large horizontal forces from the braking load. Nevertheless, there is a separate experience in the successful application of seismic isolation of railway bridges in the practice of bridge construction. Here we can highlight the seismic isolation of the Las Piedras bridges in Spain and the North Railway Bridge in Budapest and a bridge in Greece, designed by Maurer Sohnes [1]. In Russia, it should be noted a group of bridges on the Sochi-Adler line designed by Transmost OJSC with a

*Corresponding author: shoumarovss@gmail.com 
seismic isolation system, executed by the group of companies "Stroykompleks-5" [2, 3]. This article discusses just such a seismic isolation system. It is a seismic isolation device that has four main features:

Vertical and horizontal loads are transferred to different elements of a single support unit. The element, perceiving horizontal operational loads, simultaneously performs the functions of seismic isolation. The support element is made in the form of a conventional movable support part, rigid in the vertical direction. This eliminates vertical displacements of the superstructure under load;

- the seismic insulating element is made as a composite in the form of an elastic table made of steel rods (rod shock absorber) and a package of steel sheets, united by frictionmovable joints (FMJ);

- the stiffness of table $\mathrm{C}$ is selected in such a way as to minimize the design seismic loads on the support and at the same time ensure the permissible displacement of the superstructure relative to the support. According to the current norms for the design of bridges [4], horizontal displacements from the braking force $\mathrm{H}$, centrifugal force, and side impacts should not exceed the specified standard value $U_{\text {lim }}$.

$$
U=\frac{H}{C} \leq U_{\text {lim }}=0.5 \sqrt{L}
$$

This requirement is not rigorously justified. Calculations of the movements of rail strings and their efforts from operational loads show that the value of the limiting displacements can be doubled without prejudice to the requirements of the normal operation of the bridge [5].

- FMJ is included in the work when the horizontal forces from seismic impacts exceed the value $C U_{\text {lim }}$, and the friction force in the FMJ does not exceed the destructive load on the support. The schematic diagram of the considered seismic isolation system is shown in Figure.1

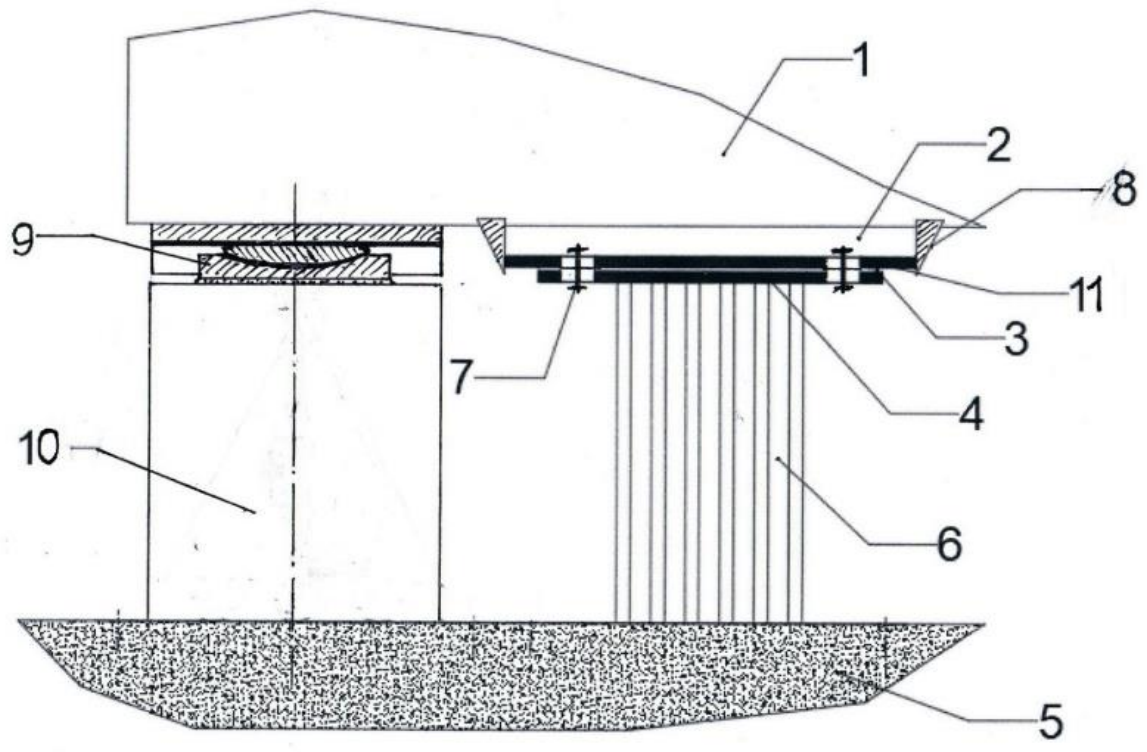

Fig. 1. Schematic diagram of the considered seismic isolation system 
Between the superstructures (1), resting on the support (5) through the support element (9) installed on the sub-bar (10), which is a conventional movable support part, for example, a ball segment one. Parallel to the support element (9), an earthquake-isolating element is installed, including an elastic element, for example, a table made of a package of steel rods (6) and a sliding element, located on the upper sheet (4) of the elastic element (6) and connected through the friction coating (3) with the additional sheet (11) using high-strength bolts (7), thus forming an FMJ, which is a sliding element. On the superstructure (1), stops (8) are installed, contacting with the additional sheet (11) and having freedom of vertical movement relative to this sheet. In this case, there is a gap between the seismic isolation element and the superstructure (2). This excludes the transfer of the vertical load to it from the superstructure, which is fully perceived by the movable support part. Under operational loads(braking of rolling stock, transverse impacts of vehicles), as well as under the action of the design earthquakes (DE), horizontal loads are transferred from the superstructure (1) to the support (5) through the stops (8) and the seismic isolation element, in which the table made of steel rods (6) works in the elastic stage. In this case, the dynamic loads on the support are reduced due to the cushioning action of the seismic isolation element. With maximum-calculated earthquake (MCE), a shift occurs in the FMJ, and the peak loads on the support are limited by the friction force in the FMJ. In this way, there is a decrease in the design loads both under the action of the DE and under the action of the MCE. The features of applying the described system for seismic protection of a bridge in Uzbekistan are considered below.

\section{Material and methods}

\subsection{Bridge description}

A 5-span railway bridge of a simple girder system is considered. The bridge diagram is shown in Figures 2 and 3.

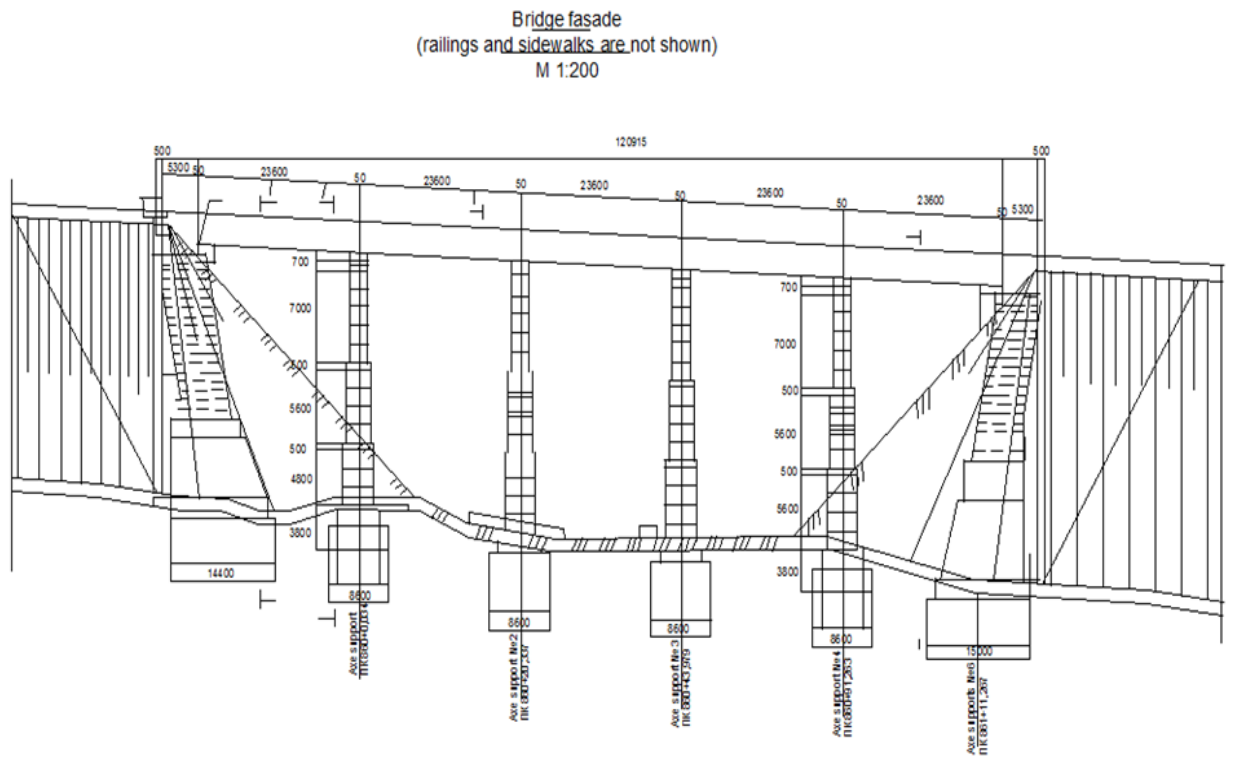

Fig. 2. General view of the overpass 
Since the bridge is split, each leg works independently. Seismic protection of supports in the most dangerous longitudinal direction is considered. With a traditional bearing design, a significant horizontal load is transferred to each support. Some results of calculating the support by the linear spectral method (LSM) are given below. For the calculation, a version of the LSM was used, including corrections to seismic loads due to modal damping [6-8]. Table 1 shows the spectral characteristics of the support.

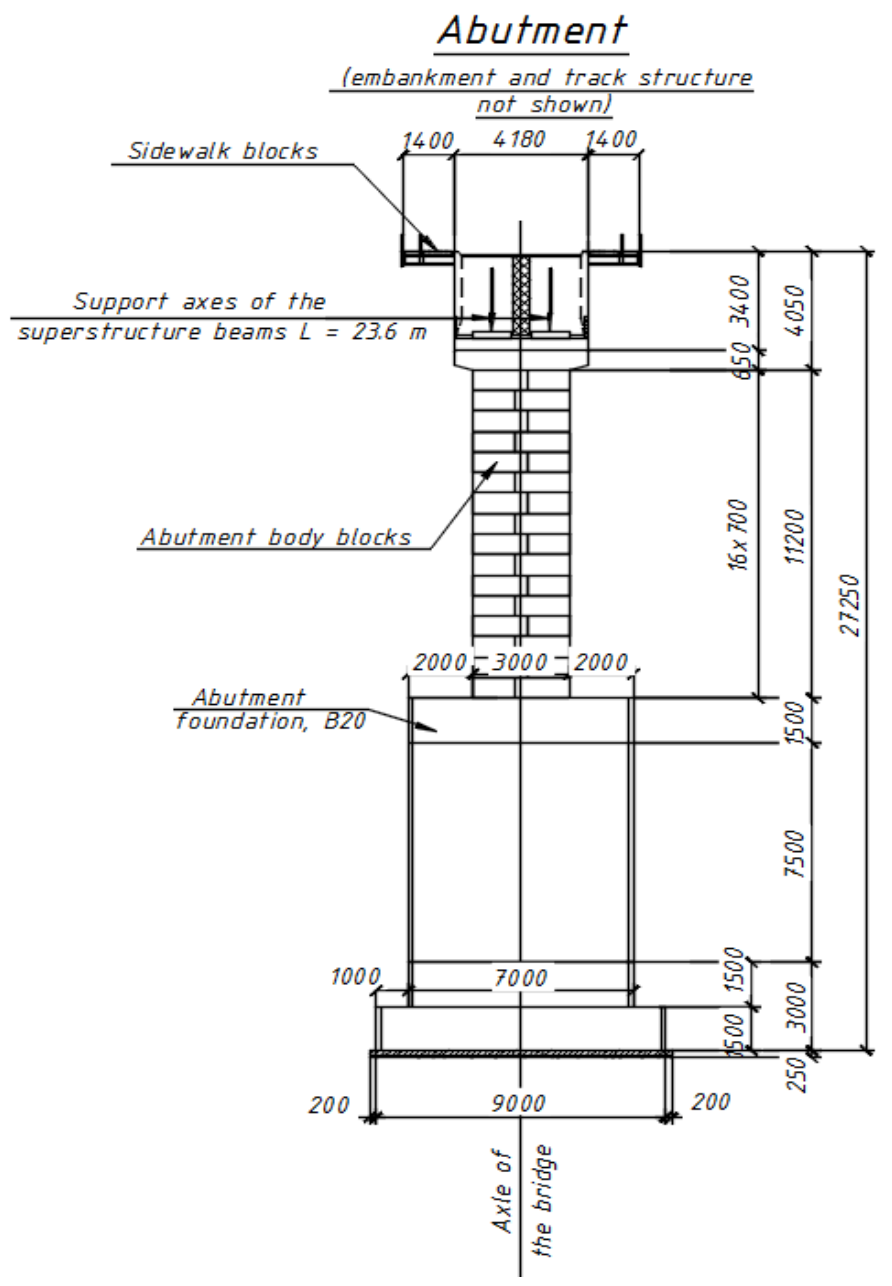

Fig. 3. Cross-section of the support

Table 1.Spectral characteristics of the system

\begin{tabular}{|c|c|c|c|c|c|c|}
\hline Form № & 1 & 2 & 3 & 4 & 5 & 6 \\
\hline Period $\mathrm{T}, \mathrm{s}$ & $\begin{array}{c}6.518 \mathrm{E} \\
-01\end{array}$ & $\begin{array}{c}1.05550 \mathrm{E} \\
-01\end{array}$ & $\begin{array}{c}4.79746 \mathrm{E}- \\
02\end{array}$ & $\begin{array}{c}2.02693 \mathrm{E}- \\
02\end{array}$ & $\begin{array}{c}1.29060 \mathrm{E}- \\
02\end{array}$ & $\begin{array}{c}8.76101 \mathrm{E}- \\
03\end{array}$ \\
\hline $\begin{array}{c}\text { Frequency k, } \\
\mathrm{rad} / \mathrm{s}\end{array}$ & $\begin{array}{l}9.6390 \\
2 \mathrm{E}+00\end{array}$ & $\begin{array}{c}5.95279 \mathrm{E} \\
+01\end{array}$ & $\begin{array}{c}1.30969 \mathrm{E} \\
+02\end{array}$ & $\begin{array}{c}3.09986 \mathrm{E} \\
+02\end{array}$ & $\begin{array}{c}4.86845 \mathrm{E}+0 \\
2\end{array}$ & $\begin{array}{c}7.17177 \mathrm{E} \\
+02\end{array}$ \\
\hline $\begin{array}{l}\text { Inelastic } \\
\text { resistance } \\
\text { coefficient }\end{array}$ & $\begin{array}{c}1.305 \mathrm{E} \\
-01\end{array}$ & $\begin{array}{c}1.262 \mathrm{E}- \\
01\end{array}$ & $1.328 \mathrm{E}-01$ & $1.053 \mathrm{E}-01$ & $1.025 \mathrm{E}-01$ & $1.000 \mathrm{E}-01$ \\
\hline
\end{tabular}



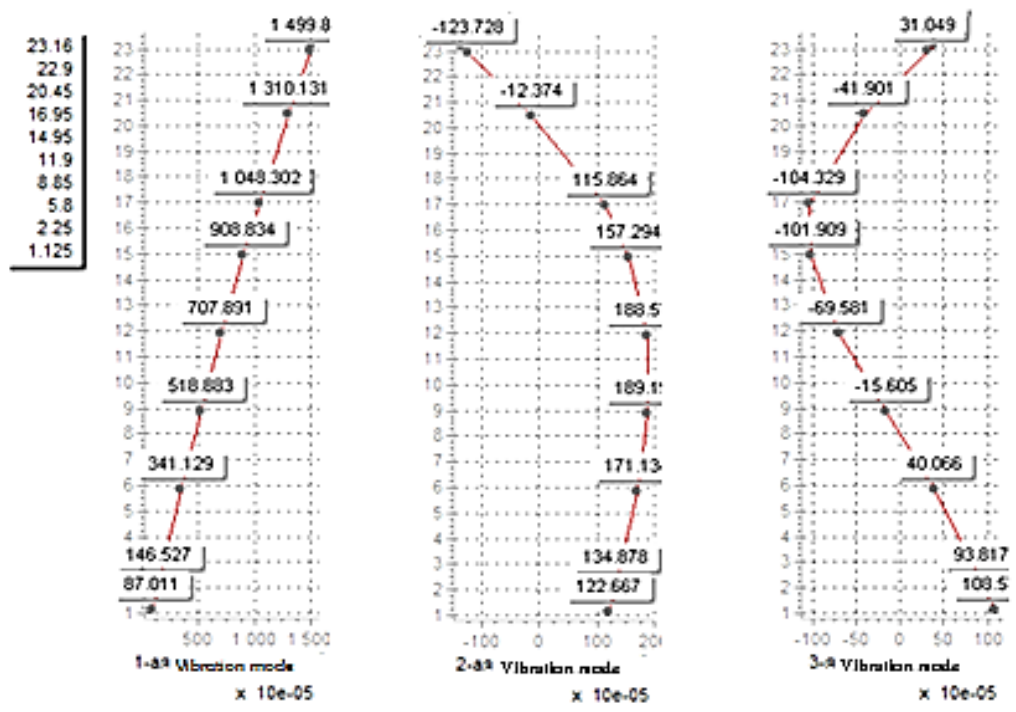

Fig. 4. The vibration modes of the support are shown in Fig. 5, the diagram of moments along the height of the support.

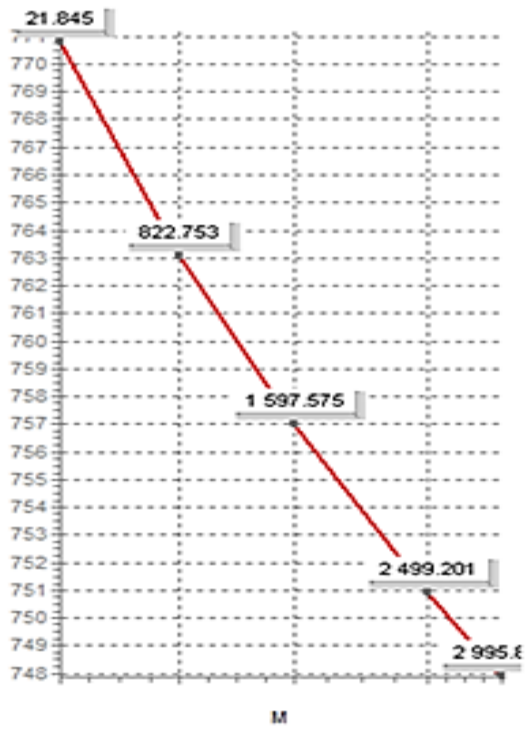

Fig. 5. Diagram of bending moments along the support height

The calculation results show that the dynamic characteristics of the support are determined by the properties of the subgrade. The damping in the first modes of vibration exceeds the damping in the support material. In concrete, the coefficient of inelastic resistance is $y=0.1$, and the modal attenuation in the first three forms is approximately 0.13 , which is due to the dissipation of energy in the base. The first mode of vibration is a rotation of the support as a rigid whole on a pliable base.

The eccentricity of the load along the base of the foundation is

$$
e=\frac{N}{M}=\frac{2995.8}{986.1}=3.04 m
$$




\section{Results and Discussion}

\subsection{Selection of seismic isolation parameters}

The selection of the seismic isolation parameters was carried out by varying the shear stiffness of the support part $[15,16]$. The dependence of the moment along the foot of the support, calculated using the LST, taking into account damping, is shown in Figure 6. First, at zero rigidity of the supporting part, we get support without a superstructure, and when the rigidity tends to infinity, we get traditional support with a rigid supporting part. It is important that, in this case, the effect of dynamic damping of support oscillations takes place, and the superstructure acts as a dynamic vibration damper (DVD). The effect is achieved approximately at $G F=1000 \mathrm{~T}$. At the same time, the moment along the foot of the support decreases to $1494 \mathrm{Tm}$. For comparison, the moment $\mathrm{M}$ along the foot of the support free from the superstructure reaches $1940 \mathrm{Tm}$, and with a rigid support part, $\mathrm{M}=2870 \mathrm{Tm}$. The results of calculating the support with the optimal stiffness of the support part are shown in Table 2.

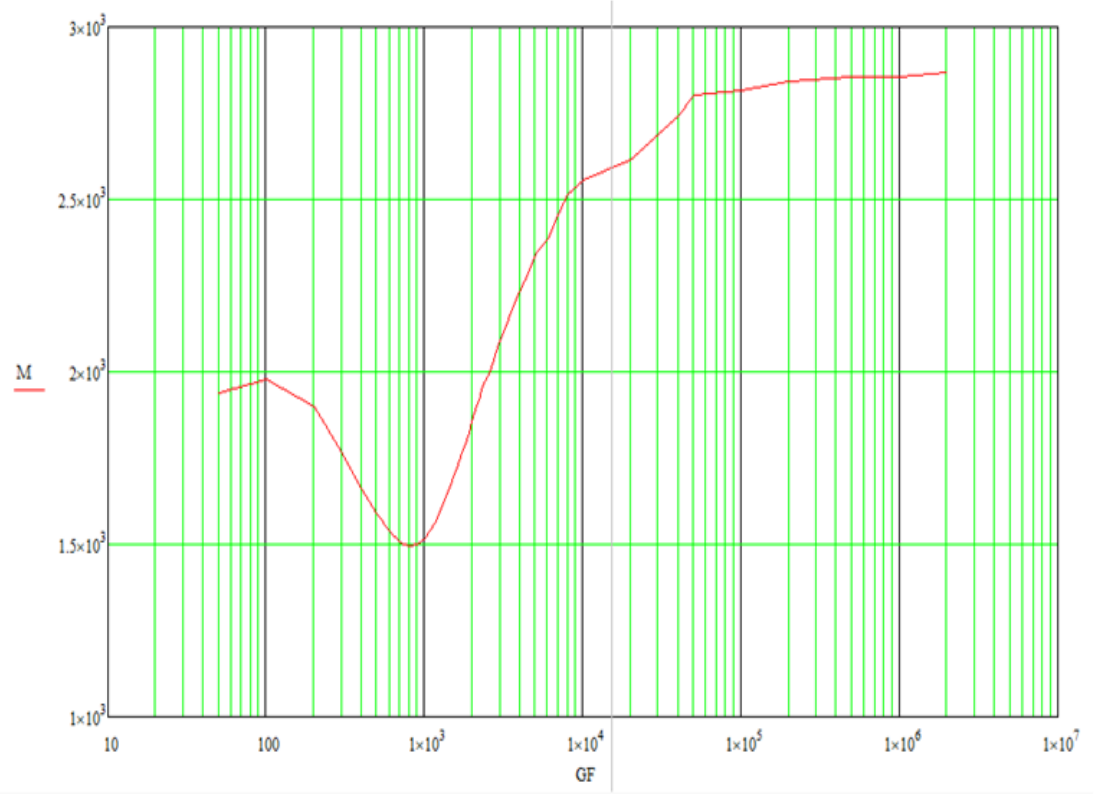

Fig. 6. Dependence of the moment along the foot of the support on the shear stiffness of seismic isolation

Let us now turn to the displacements of the superstructure relative to the support under operational loads. The graph of the dependence of these displacements on the period of the fundamental tone of the support oscillations is shown in figure 7. 


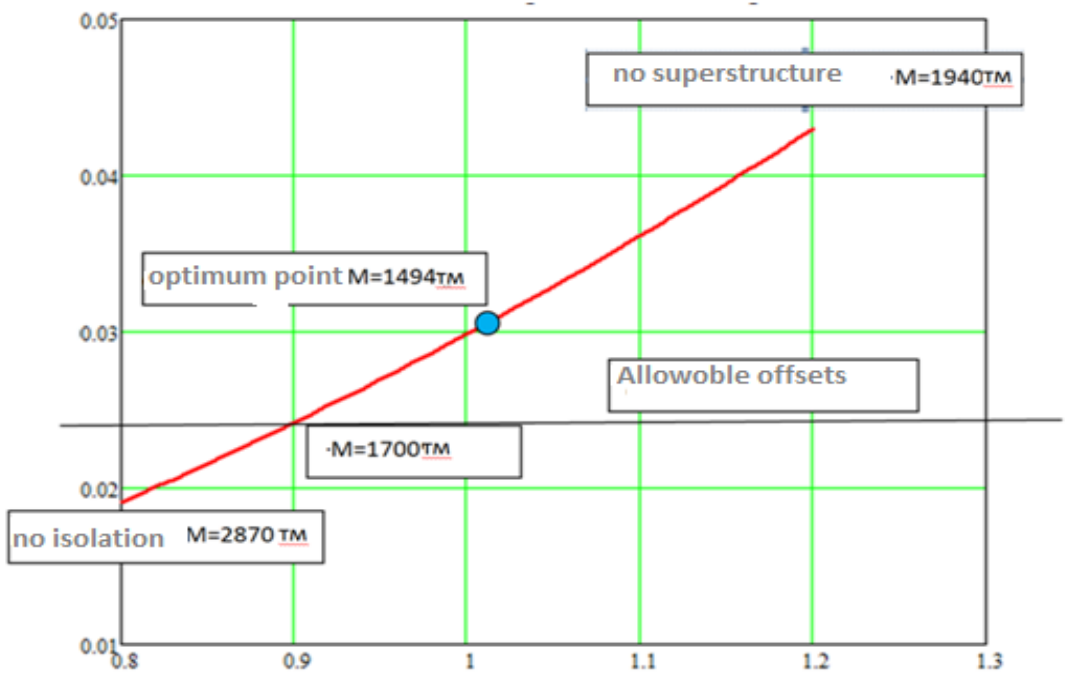

Fig. 7. Dependence of the superstructure displacements on the braking load on the seismic isolation rigidity (period)

Unfortunately, the displacements of the superstructure on the compliant support part exceed the permissible standards following formula (1). Calculations performed earlier [3, 7] show that it is possible to safely increase the permissible displacement by 2 times. However, in this case, you can simply increase the rigidity of the table, making it not optimal, but at the same time ensure that the load on the support with a span is reduced to a similar level without a span and condition (1) is fulfilled.

Table 2. Spectral characteristics of the system in the presence of a seismic isolation element

\begin{tabular}{|c|c|c|c|c|c|c|}
\hline Form № & 1 & 2 & 3 & 4 & 5 & 6 \\
\hline Period T,s & $\begin{array}{c}1.09050 \mathrm{E} \\
+00\end{array}$ & $\begin{array}{c}3.79101 \\
\mathrm{E}-01\end{array}$ & $\begin{array}{c}8.42999 \mathrm{E}- \\
02\end{array}$ & $\begin{array}{c}3.97240 \mathrm{E} \\
-02\end{array}$ & $\begin{array}{c}1.71021 \mathrm{E}- \\
02\end{array}$ & $\begin{array}{c}1.20308 \mathrm{E}- \\
02\end{array}$ \\
\hline $\begin{array}{c}\text { Frequency } \\
\text { k,rad/s }\end{array}$ & $\begin{array}{c}5.76174 \mathrm{E} \\
+00\end{array}$ & $\begin{array}{c}1.65739 \\
\mathrm{E}+01\end{array}$ & $\begin{array}{c}7.45339 \mathrm{E} \\
+01\end{array}$ & $\begin{array}{c}1.58171 \mathrm{E} \\
+02\end{array}$ & $\begin{array}{c}3.67394 \mathrm{E} \\
+02\end{array}$ & $\begin{array}{c}5.22259 \mathrm{E}+0 \\
2\end{array}$ \\
\hline $\begin{array}{c}\text { Coeff.inelasti } \\
\text { c resistance }\end{array}$ & $2.740 \mathrm{E}-01$ & $\begin{array}{c}2.070 \mathrm{E}- \\
01\end{array}$ & $1.442 \mathrm{E}-01$ & $\begin{array}{c}1.189 \mathrm{E}- \\
01\end{array}$ & $1.040 \mathrm{E}-01$ & $1.012 \mathrm{E}-01$ \\
\hline
\end{tabular}

\subsection{Selection of table parameters}

The table rods were calculated as bending beams with an embedment in the support and hinged support in the superstructure. When assessing the efforts, the additional moment from the vertical reaction on the superstructure movement relative to the support was taken into account $[3,7,9]$. Tables 3 and 4 show the results of calculating the table in two versions. One option corresponds to figure 1 , in which the vertical load is transferred to the support through the movable support part, and option 2 with the transfer of the vertical load directly to the table. In the first variant, the optimum point with a bending moment equal to $1494 \mathrm{tm}$ was considered. In this case, the horizontal reaction is $Q=42.00 \mathrm{t}$, and the table for the vertical reaction has $N=0$. In the course of the calculation, we used steel with strength $\sigma=90,000.00 \mathrm{t} / \mathrm{m}^{2}$ and modulus of elasticity $E_{s t}=20,000,000.00 \mathrm{t} / \mathrm{m}^{2}$ with optimal shear stiffness $\left(G F_{\text {opt }} / h\right)=700.00 \mathrm{t} / \mathrm{m}$, the type of fastening of the racks in the top sheet of the table: articulated. It was considered 3 types of flexible table from 50 racks, from 100 
racks, and 150 racks with an outer radius of the rack from $0.023 \mathrm{~m}$ to $0.030 \mathrm{~m}$ with a height of $1.0 \mathrm{~m}$ to $1.4 \mathrm{~m}$ for 50 racks, from $0.018 \mathrm{~m}$ to $0.025 \mathrm{~m}$ with a height from $0,9 \mathrm{~m}$ to $1.4 \mathrm{~m}$ for 100 racks and from $0.015 \mathrm{~m}$ to $0.023 \mathrm{~m}$ with heights from $0.8 \mathrm{~m}$ to $1.4 \mathrm{~m}$ for 150 racks. The results of these calculations are shown in Table 3.

Table 3 Results of calculating a table with optimal seismic isolation without transferring a vertical load to it

\begin{tabular}{|c|c|c|}
\hline Number of racks $\mathrm{n}=50$ & Number of racks $\mathrm{n}=100$ & Number of racks $\mathrm{n}=150$ \\
\hline $\mathrm{R}=0.023, \mathrm{~h}=1.000$ & $\mathrm{R}=0.018, \mathrm{~h}=0.900$ & $\mathrm{R}=0.015, \mathrm{~h}=0.800$ \\
$\mathrm{R}=0.025, \mathrm{~h}=1.100$ & $\mathrm{R}=0.020, \mathrm{~h}=1.000$ & $\mathrm{R}=0.016, \mathrm{~h}=0.900$ \\
$\mathrm{R}=0.027, \mathrm{~h}=1.200$ & $\mathrm{R}=0.021, \mathrm{~h}=1.100$ & $\mathrm{R}=0.018, \mathrm{~h}=1.000$ \\
$\mathrm{R}=0.028, \mathrm{~h}=1.300$ & $\mathrm{R}=0.023, \mathrm{~h}=1.200$ & $\mathrm{R}=0.019, \mathrm{~h}=1.100$ \\
$\mathrm{R}=0.030, \mathrm{~h}=1.400$ & $\mathrm{R}=0.024, \mathrm{~h}=1.300$ & $\mathrm{R}=0.020, \mathrm{~h}=1.200$ \\
& $\mathrm{R}=0.025, \mathrm{~h}=1.400$ & $\mathrm{R}=0.022, \mathrm{~h}=1.300$ \\
& & $\mathrm{R}=0.023, \mathrm{~h}=1.400$ \\
\hline
\end{tabular}

( $R$-outer radius of the rack, $m$; h-rack height, $m$ )

The second variant, the optimum point with a bending moment equal to $1494 \mathrm{tm}$ was also considered. In this case, the horizontal reaction is $Q=42.00$ tons, and the table for the vertical reaction has $N=137.50$ tons. In the course of the calculation, we used steel with a strength of $\sigma=90.000 .00 \mathrm{t} / \mathrm{m}^{2}$ and an elastic modulus $E_{s t}=20,000,000.00 \mathrm{t} / \mathrm{m}^{2}$ with an optimal shear stiffness $\left(G F_{\text {opt }} / h\right)=700.00 \mathrm{t} / \mathrm{m}$, the type of fastening of the struts in the top sheet of the table: hinged 3 types of a flexible table from 50 posts, from 100 posts and 150 posts are considered. When calculating the section of racks under a flexible table with an outer radius of the rack from $0.023 \mathrm{~m}$ to $0.031 \mathrm{~m}$ with a height of $0.9 \mathrm{~m}$ to $1.4 \mathrm{~m}$ for 50 racks, from $0.018 \mathrm{~m}$ to $0.026 \mathrm{~m}$ with a height of $0.8 \mathrm{~m}$ to $1.4 \mathrm{~m}$ for 100 racks and from $0.015 \mathrm{~m}$ to $0.024 \mathrm{~m}$ with a height of $0.7 \mathrm{~m}$ to $1.4 \mathrm{~m}$ for 150 racks. The results of these calculations are shown in Table 4.

Table 4 Results of calculating a table with optimal seismic isolation with the transfer of a vertical load to it

\begin{tabular}{|c|c|c|}
\hline Number of racks $\mathrm{n}=50$ & Number of racks $\mathrm{n}=100$ & Number of racks $\mathrm{n}=150$ \\
\hline $\mathrm{R}=0.023, \mathrm{~h}=0.900$ & $\mathrm{R}=0.018, \mathrm{~h}=0.800$ & $\mathrm{R}=0.015, \mathrm{~h}=0.700$ \\
$\mathrm{R}=0.025, \mathrm{~h}=1.000$ & $\mathrm{R}=0.019, \mathrm{~h}=0.900$ & $\mathrm{R}=0.016, \mathrm{~h}=0.800$ \\
$\mathrm{R}=0.026, \mathrm{~h}=1.100$ & $\mathrm{R}=0.021, \mathrm{~h}=1.000$ & $\mathrm{R}=0.017, \mathrm{~h}=0.900$ \\
$\mathrm{R}=0.028, \mathrm{~h}=1.200$ & $\mathrm{R}=0.022, \mathrm{~h}=1.100$ & $\mathrm{R}=0.019, \mathrm{~h}=1.000$ \\
$\mathrm{R}=0.030, \mathrm{~h}=1.300$ & $\mathrm{R}=0.024, \mathrm{~h}=1.200$ & $\mathrm{R}=0.020, \mathrm{~h}=1.100$ \\
$\mathrm{R}=0.031, \mathrm{~h}=1.400$ & $\mathrm{R}=0.025, \mathrm{~h}=1.300$ & $\mathrm{R}=0.021, \mathrm{~h}=1.200$ \\
& $\mathrm{R}=0.026, \mathrm{~h}=1.400$ & $\mathrm{R}=0.023, \mathrm{~h}=1.300$ \\
\hline
\end{tabular}

( $R$-outer radius of the rack, $m$; $h$-rack height, $m$ )

Of the two options for the arrangement of insulating tables, the first is preferable(with the transfer of the vertical load to the support through the movable support part), since in this case, the destruction of the table under loads exceeding the calculated ones will not lead to the fall of the superstructure. For this purpose, the table has a vertical gap and devices for transferring the horizontal load to it from the superstructure.

As part of the work performed, the work of the system was analyzed during strong earthquakes. To ensure seismic resistance, in this case, the connection of the support with the superstructure is provided using friction-moving joints (FMJ). Under loads, exceeding those dangerous for the support and the insulating table, slipping occurs in the FMJ, and the load on the support does not exceed the friction force in the FMJ. In addition to the above, the research carried out an assessment of the stress state in the rail strings. On this basis, it 
is recommended to install only longitudinally movable support parts at the end of the superstructure without a table.

\section{Conclusions}

The work performed shows that during the construction of bridge structures in earthquakeprone areas, seismic protection devices are very effective. When using light spans, it becomes possible to use them as DVD supports. As confirmed by the development of the authors described in this article and confirmed by construction experience, The most effective girder railway bridges are seismic isolation devices that include elastic elements in combination with frictionally movable joints. In this case, the spans should be supported on supports through rigid movable support parts, and seismic protection devices will perceive all operational horizontal loads. Due to the use of seismic isolation devices, it is possible not only to guarantee the reliability of the bridge during operation, but also to reduce the consumption of basic building materials by 1.3-1.5 times and, accordingly, the cost of construction.

\section{Reference}

1. Huber Peter, Realized projects of Isolation Systems for Railway Bridges in Spain, Hungary and Greece, in the PROCEEDINGS OF WORKSHOP Bridges seismic isolation and large-scale modeling Saint-Petersburg pp. 37 - 50. (2010)

2. Dolgaya A.A., Kuznetsova I.O., Uzdin A.M., Frese M.V., Shulman S.A., Seismic resistance of railway bridges. Science and transport, 4, pp 43-47. (2012)

3. Zhgutova T.V., Kuznetsova I.O., Uzdin A.M., Shulman S.A. Seismic isolation of railway bridges in Sochi. Proceedings of the meeting of the working group of the international society on seismic protection systems (ASSISi), 2011, pp 119-132.

4. SP 35.13330.2011 "Bridges and pipes". Updated edition of SNiP 2.05.03-84*.

5. Zhgutova T.V. Assessment of the track performance on bridges with seismic isolation and requirements for seismic isolation, taking into account the track performance, Bulletin of the Petersburg State University of Railways, 3, pp. 199-204 (2012).

6. Uzdin A.M., Elizarov S.V., Belash T.A. Earthquake resistant structures of transport buildings and structures. Tutorial. FGOU "Educational and methodological center for education in railway transport", p 500 (2012)

7. Uzdin A.M., Kuznetsova I.O., Seismic resistance of bridges, Saarbrucken (Germany), Palmarium, p. 450 (2014)

8. Uzdin A.M. On the account of energy dissipation in assessing the seismic resistance of transport structures, Seismic resistance of transport and network structures, Moscow, Nauka, pp. 35-44 (1986)

9. Kuznetsova I.O., Uzdin A.M., Wang Hai Bin, Zhgutova T.V., Seismic isolation of railway bridges, The world of roads, 5, pp. 40-44 (2010)

10. Anvar A., Shaumarov S., Elena S., Ulugbek S., New method for diagnostic of heat engineering and mechanical properties of cellular concrete, International Journal of Engineering and Advanced Technology, 9, 1, pp. 6885-6887 (2019)

11. Ishanovich A.A., Vladimirovna S.E., Shaumarov, S., Zabihullaevich, S.U., Ishratovich, K.S., Some aspects of the photo-optical method of estimation composition of light concrete, International Journal of Engineering and Advanced Technology, 8(5), pp. 1924-1927 (2019)

12. Adilkhodjaev, A., Makhamataliev, I., Tsoy, V., Shaumarov, S., Ruzmetov, F., Features of Forming the structure of cement concrete on second crushed stone from 
concrete scrap, International Journal of Advanced Science and Technology, 29(5), pp. 1901-1906 (2020)

13. Adilkhodjaev A., Hasanov B., Shaumarov S., Kondrashchenko V. Aerated concrete with predetermined pore parameters for the exterior walls of energy efficient buildings, IOP Conference Series: Materials Science and Engineering, 2021, 1030(1), 012006

14. Adilkhodjaev, A., Shaumarov, S., Kadir, U. New structure assessment method cell concrete, International Journal of Advanced Science and Technology, 29 (5), pp. 1889-1893 (2020)

15. Khasanov B., Vatin N., Mirzaev T., Suyunov A., Radjabov M. Analysis of the mode of squeezing out excess water for mixing concrete mixture in the process of peristaltic compaction, IOP Conference Series: Materials Science and Engineering, 2021, 1030(1), 012021

16. Adilkhodjaev, A., Tsoy, V., Khodzhaev, S., Shaumarov, S., Umarov, K., Research of the influence of silicon-organic hydrophobizer on the basic properties of cement stone and mortar, International Journal of Advanced Science and Technology, 29 (5), pp. 1918-1921 (2020)

17. Khasanov B., Vatin N., Mirzaev T., Suyunov A., Radjabov M. Physicochemical fundamentals of modifying concrete mix and concrete, IOP Conference Series: Materials Science and Engineering, 2021, 1030(1), 012022

18. U. Shermuxamedov, S.Salixanov, S.Shaumarov, F.Zokirov. Method of selecting optimal parameters of seismic-proof bearing parts of bridges and overpasses on highspeed railway lines, European Journal of Molecular and Clinical Medicine, ISSN 2515-8260, 7, pp. 1076-1084 (2020)

19. Khasanov B., Vatin N., Ismailova Z., Mirzaev T. Physical modification of concrete mix and concrete, IOP Conference Series: Materials Science and Engineering, 883(1), 012205, (2020)

20. U.Z. Shermukhamedov, T.R. Rashidov., Features of the theory of a two-mass system with a rigidly connected end of the bridge, in consideration of seismic influence on high-speed railways, European Journal of Molecular and Clinical Medicine, ISSN 2515-8260, 7, pp. 1160-1166 (2020) 